\title{
Population growth of Australian East coast humpback whales, observed from Cape Byron, 1998 to 2004
}

\author{
DAVID A. PATON*,+,\# AND ERIC KNIEST ${ }^{+}$, \\ Contactemail: dave@blueplanetmarine.com
}

\begin{abstract}
Humpback whales (Megaptera novaeangliae) that migrate past the east coast of Australia comprise part of Group V (E(i) breeding stock). From 1995 to 2004 an annual 16 day survey was conducted from Cape Byron (28 37'S, 153 38'E), the most easterly point on the Australian mainland, monitoring the peak of the humpback whale northern migration. The annual rate of increase between 1998 and 2004 of humpback whales observed off Cape Byron is $11.0 \%$ (95\% CI 2.3-20.5\%). This rate of increase is consistent with that recorded from other studies of the humpback whale population off the east coast of Australia. The large confidence intervals associated with this estimate are due to considerable inter-annual variation in counts. The most likely explanation for this being the short survey period, which may not have always coincided with the peak of migration, and in some years a large proportion of whales passed Cape Byron at a greater distance out to sea, making sightability more difficult.
\end{abstract}

KEYWORDS: HUMPBACK WHALE; SURVEY-SHORE-BASED; TRENDS; GROWTH; MIGRATION; SOUTHERN HEMISPHERE; PACIFIC OCEAN

\section{INTRODUCTION}

Humpback whales (Megaptera novaeangliae) migrate north from Antarctica, along the east and west coasts of Australia during the Austral winter, to breed and give birth in the warm waters of northern Australia. The humpback whales that pass the east coast of Australia are thought to comprise part of the group that feeds in Antarctic Area V $\left(130^{\circ} \mathrm{E}\right.$ to $\left.170^{\circ} \mathrm{W}\right)$. This group is therefore identified as 'Group V whales'. Recent studies suggest that there is sub-stock structure on the tropical breeding grounds and that these sub-stocks intermingle to at least a small degree (Garrigue et al., 2000). Group V humpback whales on their tropical breeding grounds have been divided into three sub-stocks known as: Breeding Stock E(i), those wintering off the Australian east coast; E(ii), those wintering around New Caledonia; and E(iii), those wintering around Tonga (Bannister, 2005; Olavarria et al., 2006). Breeding Stock E(i), the Australian east coast population, is the largest.

Historically, the Group V population was hunted from both land- and vessel-based operations throughout its migratory range, including the East Australian coastline and the Antarctic. Land-based whaling was conducted from several locations on the east coast of Australia, commencing in 1952. These locations included Twofold Bay, Jervis Bay, Byron Bay and Tangalooma on Moreton Island. Other locations where whaling activities occurred in the South Pacific include Norfolk Island, Cook Strait in New Zealand and Tonga. Small numbers of whales were also taken in Fiji and Vanuatu. Considerable illegal hunting of humpback whales was undertaken in Antarctic waters from 1959 to 1961 by the Soviet Union (Clapham et al., 2005; Paterson et al., 2001).

Prior to the 1950s there was little exploitation of the E(i) sub-stock. At this time the population size of the entire Group $\mathrm{V}$ population was estimated to be between 10,000 and 26,000 whales (Bannister and Hedley, 2001; Chittleborough, 1965). These figures are potentially an underestimate of the preexploitation population for Group $\mathrm{V}$ as the total number of 20 th century humpback whale catches in Area V and in breeding area (E) was 102,398 whales (Clapham et al., 2005; Clapham and Zerbini, 2006). Given the large number of whales killed and recent population modelling, it is now thought that the pre-exploitation population of the Group V whales was considerably larger than previously thought, potentially in the range of 30,000 to 40,000 humpback whales (Jackson et al., 2006).

The industrial shore-based whaling and large scale illegal pelagic whaling in the Southern Ocean resulted in a population collapse by 1962 (Chittleborough, 1965). Estimates for the remaining population vary in size from 104 for all of Group V (Bannister and Hedley, 2001) to 500 for the east Australian and New Zealand populations (Chapman, 1974; Chittleborough, 1965). These estimates are less than $5 \%$ of the pre-exploitation size. In the 45 years since 1963 , the east Australian population of humpback whales is one of a number of populations that has shown strong recovery (Brown et al., 2003; Paterson et al., 2001). The apparent lack of recovery of whales migrating past New Zealand (Childerhouse and Gibbs, 2006; Gibbs and Childerhouse, 2000), and low numbers recorded in some regions of the South Pacific (Garrigue et al., 2002; Gibbs et al., 2003), indicate that the strong increases seen in East Australia have not been seen across other parts of the South Pacific.

Shore-based observation stations have been utilised to monitor trends in a number of populations of cetaceans (Bryden et al., 1996; Buckland and Breiwick, 2002; Paterson et al., 2004). Long term studies have been conducted on humpback whales in Cape Vidal, Natal (Findlay and Best, 1996b) and North Stradbroke Island, Australia (Brown, 1996; Bryden et al., 1996; Noad et al., 2011; Paterson et al., 2004). Humpback whales migrate along the continental

\footnotetext{
* Blue Planet Marine, PO Box 919 Jamison Centre, 2614 ACT, Australia.

+ South Pacific Whale Research Consortium, clo Cook Islands Whale Research (CCRC) Box 3069, Avarua, Rarotonga, Cook Islands.

* Southern Cross University, PO Box 157, Lismore, NSW, Australia.

University of Newcastle, School of Engineering, University Drive, Callaghan, NSW 2308 Australia.
} 
inshore waters along the east coast of Australia. Bryden (1985) demonstrated that the migratory corridor between Cape Byron and Cape Moreton, was particularly narrow, with $96 \%$ of humpback whales passing within $10 \mathrm{~km}$ of headlands within this region. The width of the humpback whale migration corridor was reassessed in 1991 (Brown, 1996) and 2007 (Noad and Dunlop, 2007) and found to be consistent with the results of Bryden (1985).

The demonstrated effectiveness of using shore-based observations to monitor cetacean population trends combined with the fact that humpback whales are known to migrate close to the coast off northern New South Wales, make Cape Byron an ideal location for a long term assessment of the recovery of the E(i) Breeding Stock. This paper reports on land-based counts collected between 1998 and 2004 and the observed increase in humpback whales observed off Cape Byron during this period.

\section{MATERIALS AND METHODS}

Cape Byron is located at the most easterly point on the Australian mainland (28 $\left.38^{\circ} \mathrm{S}, 153^{\circ} 38^{\prime} \mathrm{E}\right)$. Early surveys were conducted from a location (28 $38^{\prime} 19^{\prime \prime}$ S, $\left.153^{\circ} 38^{\prime} 10^{\prime \prime} \mathrm{E}\right)$ ca. $200 \mathrm{~m}$ from the most easterly point on Cape Byron. This location has an altitude of $83 \mathrm{~m}$ and unobstructed visibility from the south-southeast to the north-northeast $\left(190^{\circ}-346^{\circ}\right)$. The Cape Byron Whale Research Project (CBWRP) operated at this location from 1995 until 1998. For the 1999 survey the CBWRP relocated to a location on the upper balcony of the Cape Byron Lighthouse. This location $\left(28^{\circ} 38^{\prime} 19^{\prime \prime} \mathrm{S}, 153^{\circ} 38^{\prime} 11^{\prime \prime} \mathrm{E}\right)$ is $173 \mathrm{~m}$ from the original landbased survey location and is $33 \mathrm{~m}$ higher (total height is $116 \mathrm{~m}$ above sea level). The new survey location has a slightly better outlook (south-southeast to the north-northwest) and has access to a reliable power supply for operating a computer. It also provides shelter during inclement weather and improved accuracy for distance determination because of the increased altitude.

The timing for the CBWRP was based upon historical whaling data collected at the Byron Bay station, which operated between 1954 and 1962 (Chittleborough, 1965). During this period 1,146 whales (primarily humpback whales) were taken near Byron Bay (Chittleborough, 1965). The survey period was chosen to coincide with the peak of the catches at the whaling station during the northern migration as it is assumed that this peak catch related to the peak in numbers of the northern migration. Observations were carried out from the land station during a 16-day period annually (i.e. last week of June and first week of July). Observations were carried out between the hours of 07:00 and 16:30 daily, weather permitting. Observations were suspended when rain made it impossible to undertake surveys; when wind strength reached a point making it impracticable to operate (25-30 knots) or lightning activity made it unsafe to be in the lighthouse. Two shifts operated each day with a 15 minute overlap, the first from 07:00 to 12:00 and the second from 11:45 to 16:30.

A software package named 'Cyclopes' was developed by staff and students from the University of Newcastle, Australia specifically for the CBWRP to improve and allow more reliable tracking of marine mammals and vessels. This real time tracking system uses an electronic theodolite interfaced to a laptop computer. The theodolite is used to acquire the location of the pod by measuring the horizontal and vertical angles to the pod, which are sent directly to the computer. Cyclopes then calculates the position of the pod correcting for tides, earth curvature and refraction. The program determines which pod was observed and plots its position on a map shown on the computer screen. Cyclopes also has the capability to record information regarding the pod's make up, activity, speed, course, distance, direction and time of observation (Kniest and Paton, 2001).

The project operated with a mean of six observers (range 2-8). Due to operational requirements, during lighthouse tours (about half an hour a couple of times a week), the survey team was reduced to two experienced observers for this short period. Survey effort was consistent over the period of the study (1998-2004). Normal survey operations included at least two observers scanning the ocean to the south and east of the Cape, and at least one scanning to the north of the Cape. For over $90 \%$ of the observation period, an experienced observer was present to confirm sightings of pods, species and composition. An observer was deemed to be experienced if they had already been involved with the project for two years, or if they had several seasons of prior field experience working with humpback whales. A research vessel worked in conjunction with the land station to undertake fluke photoidentification, confirmation of pod size, collection of behavioural data and to collect genetic samples.

Observers used both the naked eye and binoculars $(7 \times 50$ Tasco compass binoculars and $10 \times 50$ Nikon binoculars) to detect whales. Once pods were sighted, a theodolite operator (who was in addition to the dedicated observers) using a Leica TC1105 (or similar) theodolite would take fixes on the location of the pod and track movement of the pod while within the field of view of the land station. When additional personnel were available a person was dedicated to operating Cyclopes and assisting the research vessel to locate pods. At all times at least one observer was scanning for new pods.

Records of effort and weather were kept during all observation periods. Weather information including wind speed and direction, cloud cover, sea state (Beaufort), swell, visibility (estimated in $\mathrm{km}$ ) and any other factors such as smoke haze, were recorded using Cyclopes' weather recording function. In addition Cape Byron headland has a meteorological station with detailed weather information available for the site from the Australian Bureau of Meteorology.

When pods were first observed and an experienced observer confirmed the species, the observers would estimate pod composition and continually track each pod as it approached the Cape from the south. The pod composition would be adjusted (and confirmed by an experienced observer) when necessary. Careful notes were taken when pods split or joined, or there was a sudden change in behaviour. Pod composition was confirmed by the research vessel when the vessel intercepted the pod. The research vessel, under normal operating protocols, operated north of the Cape so as not to potentially disturb the movements of whales prior to passing the Cape.

Observers would monitor a pod's activity and direct the theodolite operator to the surfacing of pods. Where possible one event out of each surfacing cycle would be fixed using Cyclopes to monitor the movement pattern of the pod. Once a number of sightings of the pod were recorded, the program was able to predict the direction and speed of travel and any changes in course or speed. These data were plotted in real time on the computer screen showing the trackline of pods passing the land station. The program was extremely useful in eliminating duplicate counts of the same pod especially when pods were located close together or when a pod was lost for a period of time. 


\section{ANALYSIS}

To determine the number of whales (and pods) migrating past the Cape during the survey period, all sighting data were converted to a standard $10 \mathrm{hr}$ day, consistent with the methodology used in other migratory humpback whale surveys (Brown, 1996; Bryden et al., 1996; Findlay and Best, 1996b; Paterson et al., 2004). The standard survey period was $9.5 \mathrm{hr}$, therefore sighting rate was scaled pro-rate to a $10 \mathrm{hr}$ survey period. Due to the expansive field of view from the land station (over $180^{\circ}$ ), only pods that had crossed a line due east of the Cape during the survey period were included in the analysis. The time each pod passed the line extending east of the cape was calculated by projecting from the pod's closest observed position along a line representing its mean course and speed. These pods were included in the analysis if they were determined to have passed east of the Cape during the survey period. Only humpback whales observed travelling in a northerly direction were included in the analysis.

To avoid double counts or missing whales when pods split into separate groups or when other whales would join a previously tracked pod, the number of whales was only counted in the initial pod. After an affiliation or disaffiliation of a pod occurred, the new pods formed would be assigned new names. During analysis these pods would have the number of whales in the pod set to zero (although the pod composition is still noted). For example if pod ' $\mathrm{D}$ ' ( size $=1$ ) joined pod ' $\mathrm{H}$ ' $(\operatorname{size}=2)$, the new pod formed would be called 'H/D' with composition noted as 3 but the pod size is assumed to be zero for the sake of determining whale counts; and the new pod is not included in the count as an extra pod.

Determining which days should be excluded from the analysis due to adverse weather can be subjective. For the purposes of this analysis, the following protocol was used for the exclusion of days: (1) days with a mean sea state greater than Beaufort 3 and/or mean visibility less than $15 \mathrm{~km}$ for extended periods; and (2) days on which fewer than five hours of survey were conducted.

Each day's count was converted to a standard $10 \mathrm{hr}$ count for that day, given by:

$$
C_{i}=10 / \mathrm{h}_{\mathrm{i}} \times N_{i}
$$

Where:

$i$ is the $i^{\text {th }}$ day of the survey

$h_{i}$ is number of hours of survey for the $i^{\text {th }}$ day $\left(5 \mathrm{hr}<h_{i}<\right.$ $10 \mathrm{hr}$ )

$N_{i}$ is the number of whales that passed the survey point during the $h_{i}$ hours.

The mean $10 \mathrm{hr}$ count $\left(R_{y}\right)$ for each year was calculated from all the daily $10 \mathrm{hr}$ counts $\left(C_{i}\right.$, where $i=1$ to $D_{y}$, and $D_{y}=$ the number of days surveyed for year y). A simple linear regression was fitted to the natural log of the mean $10 \mathrm{hr}$ count for each year $\left(R_{y}\right)$ over the survey period to determine the growth rate (percentage increase per year).

A growth model has also been fitted by generalised least squares. Full details of the growth model are shown in Appendix 1.

\section{RESULTS}

Between 1998 and 2004 a total of 105 days (897hr, 45min) of land-based surveys were conducted from Cape Byron. During this period a total of 1,768 pods, comprising 3,340

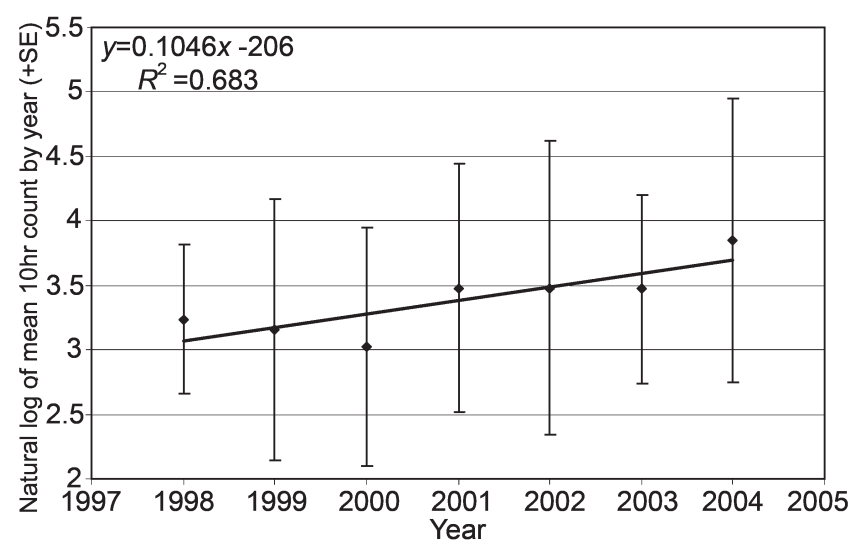

Fig. 1. Natural log of the mean $10 \mathrm{hr}$ count by year with standard errors show. A simple linear regression has been fitted.

humpback whales (including 19 neonate calves) were observed travelling north past the Cape. Nineteen pods of humpback whales (i.e. $1 \%$ of all pods seen), were observed to have a direction of travel other than in the general north direction (i.e. east, southeast or southwest). These pods were typically observed to be moving in a direction to interact with other pods of humpback whales. No pods were observed with a clear southerly migration direction during the survey. It is therefore assumed that, during the survey period all pods of humpback whales observed off Cape Byron have a clear northerly migration direction and therefore all pods were included in this analysis.

Most years of the CBWRP survey suffered from days with poor weather conditions and therefore not all days were surveyed. Other days were surveyed with below average conditions (such as rough seas) and have been eliminated from the analyses. Both 1999 and 2000 had a higher proportion of bad weather days than other years. Four days were lost due to rain in 1999 and another four days were removed because of rough seas or poor visibility.

Fig. 1 indicates the increase in the mean number of whales observed per $10 \mathrm{hr}$ for the seven years of the survey. Based on the fitting of a simple linear regression to the log of the mean $10 \mathrm{hr}$ counts for the 16-day survey period, the annual growth rate for the humpback population was estimated to be $11 \%(95 \%$ CI 2.3-20.5, see Appendix 1).

The seven-year survey had large variations in the mean distance offshore of pods as shown in Fig. 2. In 1998 and 2004, whales passed significantly closer to the Cape Byron survey station than other years except $2002 \quad(p<0.05$ ANOVA, post hoc Bonferroni Test). The overall mean number of humpback whales in each pod was $1.9 \pm 0.16$ with slightly higher values in 1998 and 2004. The mean pod speed is reasonably consistent over years (Table 1). There was an increase in the number of newborn calves observed over the survey. The number of newborn calves observed annually, is approximately 0.5 to $1 \%$ of the total number of whales observed. Most pods had a composition of one (38\%), two $(43 \%)$ or three $(12 \%)$ animals, while the rest of pods had between four to eight (7\%) animals.

\section{DISCUSSION}

The annual rate of increase between 1998 and 2004 for humpback whales observed off Cape Byron is calculated to be $11.0 \%$ (95\% CI 2.3-20.5). This annual rate of increase is consistent with results recorded at Point Lookout, North Stradbroke Island (134km north of Cape Byron) by two 


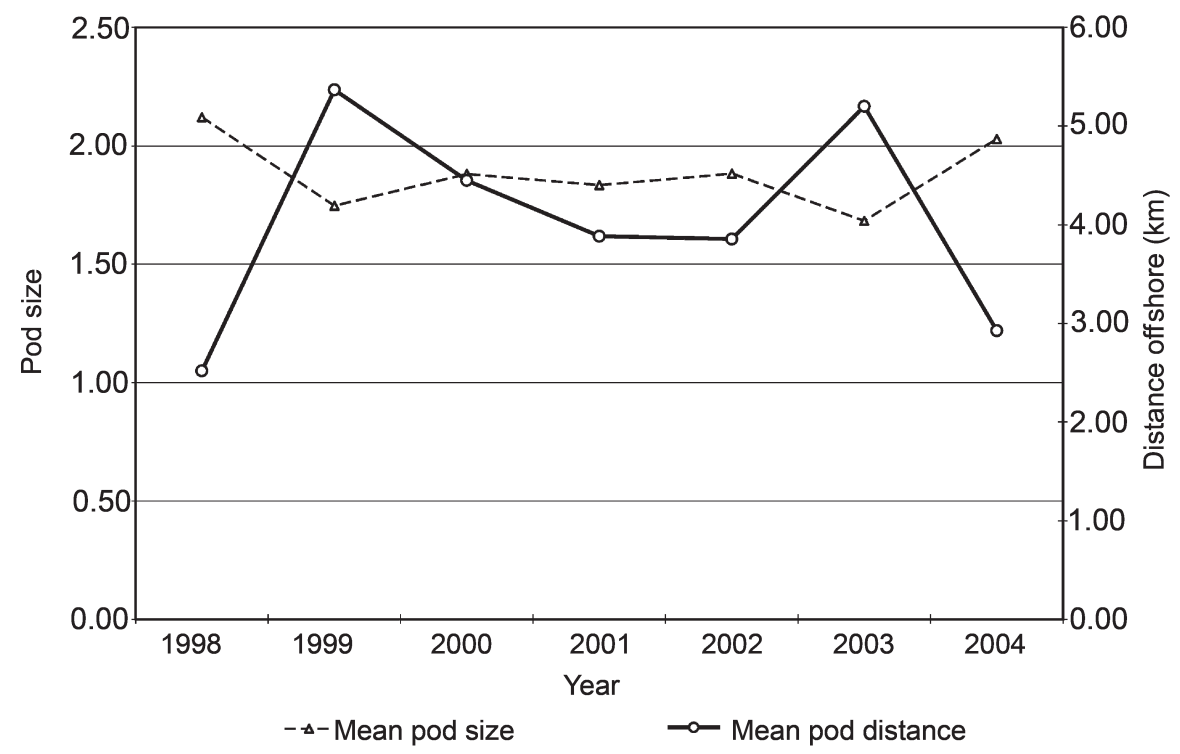

Fig. 2. Graph of the mean pod distance off shore and pod composition from 1998-2004.

independent land-based surveys. Surveys conducted by Paterson (Paterson et al., 2004) estimate a growth rate of $10.5 \%$ per annum for the humpback whale population from 1984 to 2002. Other surveys conducted by Bryden et al. (1996) and Brown (1996) reported slightly higher annual rates of population recovery of about $12.3 \%$. Brown et al. (2003) reassessed the Bryden/Brown data using more appropriate models and re-estimated the population increase (1981-2000) to be between $8.52 \%$ and $10.08 \%$. However, Noad, continuing the Bryden/Brown surveys, reported a $10.6 \%$ (95\% CI 10.1-11.1\%) for the period 1987-2004 (Noad et al., 2011) and an increase of 10.9\% (95\% CI 10.5$11.4 \%$ ) for the period 1984-2007 (Noad et al., 2008). While these population growth rates lie near or above the theoretical reproductive maximum of the species (Bannister and Hedley, 2001; Best, 1993; Brandao et al., 1999; IWC, 2008), which on the whole, are based on life history estimates for Northern Hemisphere humpback whale stocks where estimates for population growth rates are lower than determined for the southern hemisphere, (IWC, 2008), they are remarkably consistent over time with a very tight correlation between log-transformed, normalised whale counts and year (Noad et al., 2011).

While this survey provides a useful estimate of population growth rate for the E(i) breeding stock, there are several important considerations and some potential sources of bias that may influence the CBWRP estimate. There are several explanations for the observed variation in the number of whales counted per $10 \mathrm{hr}$ period over the survey period:
(1) there are large inter-annual variations in the number of humpback whales migrating up the east Australian coast;

(2) some of the surveys were influenced by bad weather or poor visibility conditions;

(3) the short (16 day) survey missed some of the peak migration period in some years; and

(4) large variations in the average pod distance out to sea may lead to differences in their sightability.

A degree of inter-annual variation is expected when monitoring a natural system. Forestell et al. (2003) suggested that El Niño-Southern Oscillation (ENSO) events may have a significant impact on fluctuations in whale numbers on the east coast of Australia. They suggested that humpback whales might migrate to other foraging areas in the highlatitude feeding grounds as a result of ENSO-related effects on food stocks. The whales might then migrate from there to different low latitude breeding grounds leading to variation in the number of whales observed between years. However, the long term survey conducted by Paterson from North Stradbroke Island shows little variation in the overall humpback whale population count over the years (Noad et al., 2011; Paterson et al., 1994; 2001; 2004); there is no indication of large fluctuations in the migrating population from year to year. Clapham and Zerbini (2006) have also suggested that the rapid growth rate of the E(i) breeding stock may be a result of immigration from other populations. While these theories are plausible, the South Pacific Whale Research Consortium recently tested this hypothesis by undertaking an assessment of fluke identification

Table 1

Yearly summary of data collected from CBWRP, 1998-2004. The average pod distance is the estimated distance from the coastline to the pod. The average pod speed is given in $\mathrm{km} / \mathrm{h}$, and distances are in kilometres.

\begin{tabular}{|c|c|c|c|c|c|c|c|c|}
\hline Year & Raw count & $10 \mathrm{hr}$ count $\pm \mathrm{SE}$ & Average pod size & Average distance & Average speed & No. of calves & Max. pod size & Max. distance \\
\hline 1998 & 375 & $25.47( \pm 1.79)$ & 2.12 & 2.52 & 6.49 & 0 & 5 (4 pods) & 8.5 \\
\hline 1999 & 229 & $23.38( \pm 2.75)$ & 1.75 & 5.37 & 6.11 & 1 & 7 (1 pod) & 13.6 \\
\hline 2000 & 302 & $20.52( \pm 2.52)$ & 1.88 & 4.45 & 5.88 & 0 & 5 (4 pods) & 15.2 \\
\hline 2001 & 522 & $32.33( \pm 2.62)$ & 1.83 & 3.88 & 6.16 & 3 & $5(1$ pod $)$ & 18.4 \\
\hline 2002 & 563 & $32.36( \pm 3.13)$ & 1.88 & 3.85 & 5.70 & 3 & 8 (1 pod) & 15.3 \\
\hline 2003 & 505 & $32.12( \pm 2.09)$ & 1.68 & 5.20 & 5.39 & 5 & 5 (2 pods) & 16.6 \\
\hline 2004 & 814 & $47.02( \pm 3.01)$ & 2.03 & 2.93 & 6.20 & 7 & 8 (1 pod) & 15.8 \\
\hline
\end{tabular}


photographs collected throughout Oceania (Breeding Stocks E(ii), E(iii) and F) and eastern Australia (Breeding Stock E(i)). This analysis, coupled with the recovery of Discovery marks from this region, indicates a very low level of interchange between eastern Australia and the Oceania region, which does not support this theory (Garrigue et al., 2011a; Garrigue et al., 2011b; Paton and Clapham, 2006).

Brown et al. (1995) report a bias in the sex ratio of humpback whales sampled off the east coast of Australia. They suggest that not all animals migrate every year as there is little reason for females who are not calving or mating to make the long migration. This may mean that, depending on environmental conditions, there may be inter-annual variation in the proportion of females undertaking migration, which in turn may lead to variation in survey counts. This issue remains unresolved with respect to eastern Australian humpback whales but has the potential to influence survey results between years.

Environmental conditions during surveys can have a significant impact on the sightability of whales. Some of the years appear to have been influenced by poorer than average weather conditions. In particular, 1999 and 2000 were badly affected by rain and poor weather and a large number of survey days were lost. Throughout the survey the average for the $10 \mathrm{hr}$ survey period was estimated only for those days with reasonable conditions. This should lead to an unbiased average from a smaller sample size but perhaps with a higher variance. Standardising effort between surveys in his manner should minimise any effect of environmental conditions on differences in whale counts between years.

The population growth estimate from this study is based on a maximum survey period of 16 days in any one year and represents an incomplete survey of the total migration period. While the assumption is that the weeks surveyed are representative of the full migration period, the accuracy of this assumption remains unknown. The survey was undertaken at the same time each year and studies of the timing of the migration have provided good evidence that migratory patterns are reasonably consistent between years, but the peak in migration may vary by up to a couple of weeks (Dawbin, 1966; Paterson et al., 2001). It is therefore likely that the two-week survey period did not always capture the entire peak of the humpback migration each year. To investigate this, data from Cape Byron can be compared with data collected at North Stradbroke $(134 \mathrm{~km}$ north of Cape Byron), which are collected over a much longer period. It takes almost one day for the humpback whales to travel from Cape Byron to Stradbroke at an average speed of $6.0 \mathrm{~km} \mathrm{hr}^{-1}$.

A comparison of $10 \mathrm{hr}$ counts averaged on a weekly basis for the equivalent two weeks (e.g. accounting for the one day travel time difference between the two sites) at Cape Byron and North Stradbroke Island can be seen in Fig. 3. While there are fluctuations between the two sets of data, the Byron count is generally less than the Stradbroke count for most years except for 2001 and 2004 where the data are very similar. Fig. 2 shows that the average pod distance is also much lower than most other years (except 1998). Because of the large variations in the Stradbroke weekly counts it is difficult to determine if the Cape Byron survey was conducted at the height of the peak migration period; it appears the peak migration often spans about a four-week period usually starting one week before the Byron survey starts.

The distance at which the humpback whales pass the Cape varies considerably within and between years. All years of the Cape Byron survey except 1998 had observations of pods more than $10 \mathrm{~km}$ offshore and most years had observations of pods that were $15 \mathrm{~km}$ or more offshore. The estimated average percentage of pods that travelled more than $10 \mathrm{~km}$ offshore was 3.0\% (range $0-16 \%$ ); and the average for pods passing more than $5 \mathrm{~km}$ out was $35.0 \%$ (range $13.4-53.0 \%$ ). A preliminary vessel-based survey across the continental shelf off Cape Bryon conducted in 1996 (CBWRP, unpublished data) indicated that approximately $90 \%$ of humpback whales passing Cape Byron did so within 10km of the shoreline; the remainder travelling up to $23 \mathrm{kms}$ offshore. Had the CBWRP survey been conducted in 1998 or 2004 one would expect similar results to those of the present study; while quite different results would have most likely been obtained had the CBWRP study been completed in 1994 or 2003. Findlay and Best (Findlay and Best, 1996a)
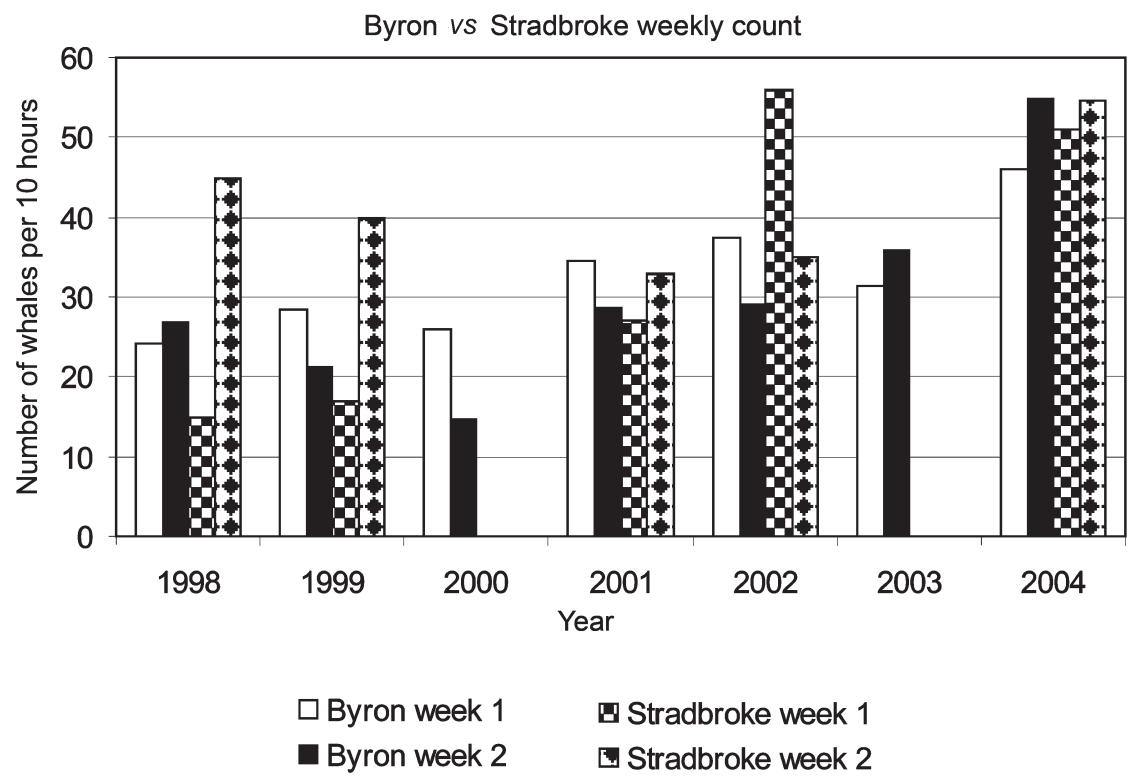

Fig. 3. Byron and North Stradbroke Island weekly 10 hours counts. The 1998 to 2002 Stradbroke Figures are from Paterson's surveys (Paterson et al., 2001; 2004) and the 2004 Stradbroke Figures are from Noad et al. (2011). 
found that between $40 \%-50 \%$ of whales travelling from $6-$ $10 \mathrm{~km}$ offshore can be missed during counts. About $37 \%$ of whales were measured further than $6 \mathrm{~km}$ from the shoreline in 1999, 2000 and 2003. This implies there could be an error of about $18 \%$ in the counts for these years. Only $\sim 10 \%$ of whales were observed more than $6 \mathrm{~km}$ from the shoreline in 1999 and 2004.

Two factors affect precision of the rate of growth calculated from the Cape Byron surveys: (1) precision of $R$; and (2) number of survey years. Power calculations based on what is known about the migration patterns of this population could be conducted to determine whether annual surveys should be continued or whether a longer survey each second or third year would result in a greater improvement in precision per additional survey.

The 2004 count may be viewed as an outlier as it appears to be inflated compared to other years. However, it may in fact be a more reliable count than most years due to good weather conditions and the average pod distance offshore being less than other years. In addition, 2004 was the last year of the survey period and therefore will have the highest count for this study due to the population growth rate and this will further exaggerate this perceived bias. Some of the other years of the survey (2000 and 2003) have low counts of whales, which may have been a result of the greater average pod distance offshore and prevailing weather conditions. This may explain the difference between the growth rate calculated from the present study $\left(11 \%, R^{2}=\right.$ 0.683 ) and the plausible IWC (2008) maximum biological increase of around $10.3 \%$. A weighted least squares model can be used to improve the estimated growth rate of the humpback population by partly removing this bias. The weight (or variance) for each year's $10 \mathrm{hr}$ count $\left(R_{y}\right)$ could be based on the standard error for each day's count $\left(C_{i}\right)$ for that year. However the standard error generally increased with the increasing numbers of whales that passed each year, therefore the standard error for each year is divided by the average $10 \mathrm{hr}$ count for that year to determine the normalised weight. The weighted least squares linear regression produced a growth rate of $10.1 \%$ with a slightly improved solution $\left(R^{2}=0.713\right)$.

The data collected by the CBWRP may be better suited for detailed studies of humpback behaviour patterns. The data may also be useful in studying the cause and effect of variables that influence observing conditions. A number of different relationships between pod behaviour and distribution patterns along with other factors that influence viewing conditions can be further studied.

\section{ACKNOWLEDGEMENTS}

The CBWRP is a large undertaking each year and would not be possible without the help of a number of people. Many thanks go out to Guy Holloway, Sue Walker and Bob Beale from the NSW National Parks and Wildlife Service, and Nick Rigby formerly from the Cape Byron Trust, for their help and co-operation with running the survey from the Cape Byron headland and lighthouse. Our gratitude is also extended to staff from Southern Cross University/Southern Cross University Whale Research Centre, especially Professors Peter Baverstock and Peter Harrison, for their assistance with organising the surveys. Additional support from Robyn McCulloch (Department of Environment and Heritage), Mike Noad, Doug Cato, John Sugarman (AMSA), Wayne Pellow, Steve King, Mark Johnson (NSW NPWS), and Ted Taylor (Cape Byron Coastal Patrol) is also much appreciated. Constructive comment on the draft manuscript was received from Peter Baverstock, Simon Childerhouse and two anonymous reviewers. Lyndon Brookes provided statistical advice and assistance with the growth model used in Appendix 1.

Special thanks goes out to all the volunteers especially Merv Wicker, Adrian Oosterman, Dan Burns, Megan Anderson, Wendy Stewart, Simon Walsh, and Grant Baker for their expert assistance over many years of the survey. And the authors are very grateful to all the partners of all the volunteers and organisers, especially Susanne Paton and Elizabeth Kniest.

The CBWRP is undertaken under a Scientific Research Permit issued by the Department of the Environment, Water, Arts and Heritage under the Environment Protection and Biodiversity Conservation Act 1999. (permit number E2001/0005) and the New South Whales National Parks and Wildlife Service (permit number S10403).

\section{REFERENCES}

Bannister, J.L. 2005. Intersessional Working Group on Southern Hemisphere humpback whales: revised tables by breeding stock (as at 1 May 2005). Paper SC/57/SH11 presented to the IWC Scientific Committee, June 2005, Ulsan, Korea (unpublished). 15pp. [Paper available from the Office of this Journal]

Bannister, J.L. and Hedley, S.L. 2001. Southern Hemisphere group IV humpback whales: their status from recent aerial survey. Mem. Queensl. Mus. 47(2): 587-98.

Best, P.B. 1993. Increase rates in severely depleted stocks of baleen whales. ICES J. Mar. Sci. 50(3): 169-86.

Brandao, A., Butterworth, D.S. and Brown, M.R. 1999. Maximum possible humpback whale increase rates as a function of biological parameter values. J. Cetacean Res. Manage. (Suppl.) 2: 192-93.

Brown, M.R. 1996. Population biology and migratory characteristics of east Australian humpback whales Megaptera novaeangliae. PhD thesis, University of Sydney. 322pp.

Brown, M.R., Corkeron, P.J., Hale, P.T., Schultz, K.W. and Bryden, M.M. 1995. Evidence for a sex-segregated migration in the humpback whale (Megaptera novaeangliae). Proc. R. Soc. Lond. Ser. B. 259: 229-34.

Brown, M.R., Field, M.S., Brown, C.E. and Bryden, M.M. 2003. Rates of increase for east Australian humpback whales, Megaptera novaengliae, from 1981-2000. Paper SC/55/SH21 presented to the IWC Scientific Committee, May 2003, Berlin (unpublished). 7pp. [Paper available from the Office of this Journal].

Bryden, M.M. 1985. Studies of humpback whales (Megaptera novaeangliae), Area V. pp.115-23. In: Ling, J.K. and Bryden, M.M. (eds). Studies of Sea Mammals in South Latitudes. South Australian Museum, Adelaide.

Bryden, M.M., Brown, M.R., Field, M.S., Clarke, E.D. and Butterworth, D.S. 1996. Survey of humpback whales (Megaptera novaeangliae) off eastern Australia, 1996. Report prepared for the Australian Nature Conservation Agency, Canberra (unpublished). 77pp. [Available from the Australian Department of the Environment, Water, Heritage and the Arts].

Buckland, S.T. and Breiwick, J.M. 2002. Estimated trends in abundance of eastern Pacific gray whales from shore counts (1967/68 to 1995/96). J. Cetacean Res. Manage. 4(1): 41-48.

Chapman, D.G. 1974. Status of the Antarctic rorqual stocks. pp.218-38. In: Schevill, W.E. (eds). The Whale Problem, A Status Report. Harvard University Press, Massachusetts. $\mathrm{x}+419 \mathrm{pp}$.

Childerhouse, S. and Gibbs, N. 2006. Preliminary report for Cook Strait humpback whale survey winter 2006. Unpublished report WGNHO264433 to Department of Conservation, PO Box 10-420, Wellington, New Zealand. 6pp. [Available from the author].

Chittleborough, R.G. 1965. Dynamics of two populations of the humpback whale, Megaptera novaeangliae (Borowski). Aust. J. Mar. Freshwater Res. 16(1): 33-128.

Clapham, P., Mikhalev, Y., Franklin, W., Paton, D., Baker, S. and Brownell, R.L., Jr. 2005. Catches of humpback whales in the Southern Ocean, 1947-1973. Paper SC/57/SH6 presented to the IWC Scientific Committee, June 2005, Ulsan, Korea (unpublished). 13pp. [Paper available from the Office of this Journal].

Clapham, P. and Zerbini, A. 2006. Is social aggregation driving high rates of increase in some Southern Hemisphere humpback whale populations? Paper SC/58/SH3 presented to the IWC Scientific Committee, May 2006, St Kitts and Nevis, West Indies (unpublished). 12pp. [Paper available from the Office of this Journal]. 
Dawbin, W.H. 1966. The seasonal migratory cycle of humpback whales. pp.145-70. In: Norris, K.S. (eds). Whales, Dolphins, and Porpoises. University of California Press, Berkeley and Los Angeles. xv+789pp.

Findlay, K.P. and Best, P.B. 1996a. Assessment of heterogeneity in sighting probabilities of humpback whales within viewing range of Cape Vidal, South Africa. Mar. Mammal Sci. 12(3): 335-53.

Findlay, K.P. and Best, P.B. 1996b. Estimates of the numbers of humpback whales observed migrating past Cape Vidal, South Africa, 1988-1991. Mar. Mammal Sci. 12(3): 354-70.

Forestell, P.H., Kaufman, G. and Chaloupka, M. 2003. Migratory characteristics of humpback whales (Megaptera novaeangliae) in Hervey Bay and the Whitsunday Islands, Queensland, Australia: 1993-1999. Final report to the Environmental Protection Agency, Queensland Parks and Wildlife Service Brisbane, Australia, October 2003, Brisbane, Australia.

Garrigue, C., Aguayo, A., Amante-Helwig, V.L.U., Baker, C.S., Caballero, P., Clapham, P., Constantine, R., Denkinger, J., Donoghue, M., FlorezGonzalez, L., Greaves, J., Hauser, N., Olavarria, C., Pairoa, C., Peckham, H. and Poole, M. 2002. Movements of humpback whales in Oceania, South Pacific. J. Cetacean Res. Manage. 4(3): 255-60.

Garrigue, C., Constantine, R., Poole, M.M., Hauser, N., Clapham, P., Donoghue, M., Russell, K., Paton, D., Mattila, D.K., Robbins, J. and Baker, C.S. 2011a. Movement of individual humpback whales between wintering grounds of Oceania (South Pacific), 1999 to 2004. J. Cetacean Res. Manage. (special issue 3): 257-281.

Garrigue, C., Forestell, P., Greaves, J., Gill, P., Naessig, P. and Baker, C.S 2000. Migratory movement of humpback whales (Megaptera novaeangliae) between New Caledonia, East Australia and New Zealand. J. Cetacean Res. Manage. 2(2): 101-10.

Garrigue, C., Franklin, T., Constantine, R., Russell, K., Burns, D., Poole, M.M., Paton, D., Hauser, N., Oremus, M., Childerhouse, S., Mattila, D.K., Gibbs, N., Franklin, W., Robbins, J., Clapham, P. and Baker, C.S. 2011b. First assessment of interchange of humpback whales between Oceania and the east coast of Australia. J. Cetacean Res. Manage. (special issue 3): 269-274.

Gibbs, N. and Childerhouse, S. 2000. Humpback whales around New Zealand. Conservation Advisory Science Notes 287: 32pp. Department of Conservation. Wellington, NZ.

Gibbs, N., Paton, D.A., Childerhouse, S., McConnell, H. and Oosterman, A. 2003. Final Report of a survey of whales and dolphins in the Lomaiviti Island Group, Fiji 2003. Final report to the Department of Environment and Heritage, Canberra, Australia (unpublished). [Available from the Australian Government, GPO Box 787, Canberra, ACT 2601, Australia].

International Whaling Commission. 2008. Report of the Scientific Committee. Annex H. Report of the sub-committee on other Southern Hemisphere whale stocks. J. Cetacean Res. Manage. (Suppl.) 10:207-24.

Jackson, J.A., Zerbini, A., Clapham, P., Garrigue, C., Hauser, N., Poole, M. and Baker, C.S. 2006. A Bayesian assessment of humpback whales on breeding grounds of eastern Australia and Oceania (IWC Stocks E, E1,
E2 and F). Paper SC/A06/HW52 presented to the IWC Workshop on Comprehensive Assessment of Southern Hemisphere Humpback Whales, Hobart, Tasmania, 3-7 April 2006 (unpublished). 19pp. [Paper available from the Office of this Journal].

Kniest, E. and Paton, D.A. 2001. Temporal GIS for marine mammal research. Paper presented at the 14th Biennial Conference on the Biology of Marine Mammals, Vancouver, Canada, 28 November - 3 December 2001.

Noad, M. and Dunlop, R.A. 2007. Abundance estimates of the east Australian humpback whale population. Progress report for the Australian Department of the Environment and Water Resources (unpublished). [Report available from Australian Department of the Environment and Water, Arts and Heritage, GPO Box 787 Canberra, 2601 ACT Australia]. Noad, M.J., Dunlop, R.A., Paton, D. and Cato, D.H. 2008. An update of the east Australian humpback whale population (E1) rate of increase. Paper SC/60/SH31 presented to the IWC Scientific Committee, June 2008, Santiago, Chile (unpublished). 13pp. [Paper available from the Office of this Journal].

Noad, M.J., Dunlop, R.A., Paton, D. and Cato, D.H. 2011. Absolute and relative abundance estimates of Australian east coast humpback whales (Megaptera novaeangliae). J. Cetacean Res. Manage. (special issue 3): 243-252.

Olavarria, C., Anderson, M., Paton, D.A., Burns, D., Brasseur, M., Garrigue, C., Hauser, N., Poole, M., Caballero, S., Flórez-Gonzalez, L. and Baker, C.S. 2006. Eastern Australian humpback whale genetic diversity and their relationship with Breeding Stocks D, E, F and G. Paper SC/58/SH25 presented to the IWC Scientific Committee, May 2006, St Kitts and Nevis, West Indies (unpublished). 6pp. [Paper available from the Office of this Journal].

Paterson, R., Paterson, P. and Cato, D.H. 1994. The status of humpback whales, Megaptera novaeangliae, in east Australian waters. Biol. Conserv. 47: 33-48.

Paterson, R., Paterson, P. and Cato, D.H. 2001. Status of humpback whales (Megaptera novaeangliae) in east Australia at the end of the 20th Century. Mem. Queensl. Mus. 47(2): 579-86.

Paterson, R., Paterson, P. and Cato, D.H. 2004. Continued increase in east Australian humpback whales in 2001, 2002. Mem. Queensl. Mus. 49(2): 712.

Paton, D.A. and Clapham, P.J. 2006. An assessment of Southern Hemisphere humpback whale population structure and migratory interchange based on Discovery mark data. Paper SC/A06/HW33 presented to the IWC Workshop on Comprehensive Assessment of Southern Hemisphere Humpback Whales, Hobart, Tasmania, 3-7 April 2006 (unpublished). $19 \mathrm{pp}$. [Paper available from the Office of this Journal].

Pinheiro, J.C. and Bates, D.M. 2000. Mixed effects models in S and S-PLUS Springer-Verlag, New York.

$R$ Development Core Team. 2006. $R$ : A language and environment for statistical computing. R Foundation for Statistical Computing, Vienna, Austria. ISBN 3-900051-07-0, URL: http://www.R-project.org.

\section{Appendix 1 \\ GROWTH IN 10HR SIGHTING RATES IN BYRON BAY 1998-2004}

The data analysed were:

\begin{tabular}{ccc}
\hline Year & Rate & $\ln ($ rate $)$ \\
\hline 1 & 25.471 & 3.238 \\
2 & 23.375 & 3.152 \\
3 & 20.518 & 3.021 \\
4 & 32.331 & 3.476 \\
5 & 32.357 & 3.477 \\
6 & 32.118 & 3.469 \\
7 & 47.020 & 3.851 \\
\hline
\end{tabular}

A growth model was fitted by generalised least squares $(\mathrm{REML})^{1}$ according to the function:

$$
\ln (\text { rate })_{\text {time }}=\beta_{0}+\beta_{1} * \text { time }+\varepsilon_{\text {time }} \text {. }
$$

${ }^{1}$ Using function GLS in package nlme (Pinheiro and Bates, 2000) in program $R$ ( $R$ Development Core Team, 2006).
In terms of rate:

$$
\text { rate }_{\text {time }}=e^{\beta_{0} *} e^{\beta_{1} * \text { time } *} e^{\varepsilon_{\text {time }}} .
$$

The parameter estimates on the log scale with $95 \%$ confidence intervals were:

$$
\begin{aligned}
& \beta_{0}=[2.598<2.965<3.332] ; \\
& \beta_{1}=[0.022<0.105<0.187]
\end{aligned}
$$

The growth parameter on the rate scale with $95 \%$ confidence interval was (by back-transformation):

$$
e^{\beta_{1}}=[1.02<1.11<1.21] ;
$$

i.e. the estimated growth rate with $95 \%$ confidence interval was $2.3 \%<11.0 \%<20.5 \%$. 
This cannot be correctly stated as mean $\pm 95 \% \mathrm{CI}$ because the interval was not symmetric about the estimate.

RSQ for the model was 0.683 .

A plot of the autocorrelation function (ACF) on the residuals indicated little serial correlation structure and a second model which fitted an AR1 structure was found not to be a significantly better fit than the original model by the likelihood ratio test $(p=0.994)$. The estimate of the AR1 parameter with $95 \%$ confidence interval was:

$$
\operatorname{phi}(A R 1)=[-0.864<0.006<0.868] \text {. }
$$

The estimated growth rate with $95 \%$ confidence interval from the AR1 model was

$$
2.3 \%<11.0 \%<20.5 \% \text {. }
$$

